\title{
ANÁLISE DA CAPACIDADE COMBINATÓRIA EM BERINJELA ${ }^{(1)}$
}

\author{
DERLY JOSÉ HENRIQUES DA SILVA ${ }^{(2)}$, CYRO PAULINO DA COSTA ${ }^{(3)}$, VICENTE WAGNER \\ DIAS CASALI (2), LUÍZ ANTÔNIO DOS SANTOS DIAS ${ }^{(4)} \&$ COSME DAMIÃO CRUZ (4)
}

\section{RESUMO}

Cinco acessos de berinjela (Solanum melongena L.) - 1: PI 206472; 2: 'Long green'; 3: 'Campineira'; 4: 'Flórida Market' e 5: 'E-22' - e os seguintes híbridos entre eles, $1 \times 3 ; 1 \times 4 ; 2 \times 4 ; 2 \times 5$ e $3 \times 5$ de frutos comerciais, foram avaliados quanto ao comprimento médio, ao diâmetro médio, ao peso médio, ao número médio por planta e à produção de frutos. As médias dos híbridos $1 \times 2,1 \times 5,2 \times 3,3 \times 4$ e 4 × 5 foram preditas, com base no método para dialelo circulante. O objetivo deste estudo foi identificar acessos e híbridos de berinjela promissores para programas de melhoramento. A análise dialélica demonstrou a predominância dos efeitos gênicos aditivos para todos os caracteres analisados. Com base nas estimativas de capacidade geral de combinação, os acessos PI 206472 e 'Campineira' foram indicados para programas de melhoramento intrapopulacional. Entre os híbridos analisados e preditos $1 \times 3,1 \times 4,1 \times 5$, e $3 \times 5$ apresentaram potencial para exploração comercial.

Termos de indexação: Solanum melongena L.; berinjela; análise dialélica, capacidade combinatória; heterose.

\footnotetext{
(1) Recebido para publicação em 13 de março de 1998 e aceito em 21 de novembro de 1998.

(2) Departamento de Fitotecnia/UFV - 36571-000 Viçosa (MG).

(3) Departamento de Horticultura, ESALQ/USP, Caixa Postal 9, 13418-900 Piracicaba(SP).

(4) Departamento de Biologia Geral/UFV 36571-000 Viçosa (MG).
} 


\section{ABSTRACT \\ COMBINING ABILITY ANALYSIS IN EGGPLANT}

A total of five eggplant accessions 1: PI 206472, 2: 'Long green', 3: 'Campineira', 4: 'Flórida Market' and 5: 'E-22' - and the hybrids 1 x 3; 1 x 4; 2 x 4; $2 \times 5$ and $3 \times 5$, were evaluated with regard to the average of length, diameter, and weight of commercial fruits, and average of number of fruits per plant and fruit yield. The average of hybrids $1 \times 2,1 \times 5,2 \times 3,3 \times 4$, and $4 \times 5$ were predicted, based on partial diallel cross methodology. The objective of this study was to identify both favorable accessions and hybrids for breeding programs. The additive genetic effects were shown to be the most important for all traits analyzed. Accessions PI 206472 and 'Campineira' were indicated for intrapopulational breeding programs based on general combining ability. Among the analyzed and predicted hybrids $1 \times 3,1 \times 4,1 \times 5$, and $3 \times 5$ presented potential for commercial exploitation.

Index terms: Solanum melongena L.; eggplant; dialelic analysis; combining ability; heterosis.

\section{INTRODUÇÃO}

A berinjela (Solanum melongena L.) sempre foi considerada hortaliça de importância secundária, porém, em vista do crescente interesse da população em consumir produtos de origem vegetal, livres de calorias excessivas e de colesterol, seu volume comercializado vem aumentando continuamente (Noda, 1980; Boletim Mensal Ceagesp, 1994).

Os programas de melhoramento existentes buscam linhagens mediante autofecundações sucessivas, que possibilitem a obtenção de híbridos produtivos e com frutos uniformes. Nesse contexto, os cruzamentos dialélicos se mostram bastante eficientes, por avaliar as populações "per se" e as respectivas combinações híbridas (Ramalho et al., 1993).

De acordo com Russel \& Eberhart (1975), o estudo da capacidade combinatória de grande número de acessos, por meio de cruzamentos dialélicos, torna-se impraticável em função do número de polinizações necessárias e dificuldades das operações de campo. Por outro lado, ao se avaliar pequeno número de acessos e combinações híbridas, os estimadores da CGC (capacidade geral de combinação) ficam sujeitos a grande variação residual, e o reduzido número de graus de liberdade, associado aos efeitos da CEC (capacidade específica de combinação), pode dificultar os testes estatísticos (Cruz \& Regazzi, 1994). E ainda, a análise de pequeno número de acessos reduz a probabilidade de encontrar as melhores combinações híbridas.

Para contornar tais problemas, Kempthorne \& Curnow (1961) apresentaram o esquema de dialelo circulante, em que são avaliados $\mathbf{p}$ acessos, representados em $\mathbf{s}$ combinações híbridas/genitor, onde $\mathbf{s}$ é menor que o número de combinações híbridas exigidas nos dialelos de Hayman, Griffing etc. (Cruz \& Regazzi, 1994), possibilitando, assim, analisar maior número de acessos, com menor número de polinizações e menor dispêndio de recursos. Gonçalves (1987) e Dantas (1988) enfatizaram a eficiência desse método do ponto de vista prático, ao estimarem a capacidade geral de combinação dos acessos, a partir de reduzido número de combinações híbridas. Os objetivos deste trabalho foram: (a) avaliar a capacidade geral de combinação de cinco acessos de berinjela, utilizando-se o esquema de análise dialélica circulante; e (b) indicar possíveis combinações híbridas superiores. 


\section{MATERIAL E MÉTODOS}

Cinco acessos de berinjela (S. melongena L.) pertencentes ao banco de germoplasma de hortaliças do Departamento de Genética da ESALQ/USP, foram analisados como genitores: 1: PI 206472; 2: 'Long green'; 3: 'Campineira'; 4: 'Flórida Market' e 5 - 'E -22', e os seguintes híbridos entre eles: 1 x $3 ; 1$ x 4; 2 x $4 ; 2$ × 5 e 3 × 5 . Os demais cruzamentos, $1 \times 2,1 \times 5,2$ x $3,3 \times 4$ e $4 \times 5$, tiveram suas médias preditas de acordo com o método desenvolvido para dialelo circulante por Kempthorne \& Curnow (1961), com número de combinações híbridas por genitor (s) igual a 2 .

$\mathrm{O}$ experimento foi realizado em Piracicaba (SP), em delineamento em blocos ao acaso com três repetições e parcelas de oito plantas. As quatro plantas centrais constituíram a parcela útil e os tratos culturais foram executados conforme Filgueira (1982).

Efetuaram-se seis colheitas, em intervalos de sete dias, avaliando-se os seguintes caracteres, no ponto de colheita comercial:

1) Comprimento médio de frutos comerciais (CMFC), em centímetro;

2) Diâmetro médio de frutos comerciais (DMFC), medido na parte de maior diâmetro $(\mathrm{cm})$;

3) Peso médio ${ }^{(5)}$ de frutos comerciais (PMFC), em grama/fruto;

4) Número médio de frutos comerciais por planta (NMFP); e

5) Produção total de frutos comerciais/planta (PROD), em grama/planta.

Nas análises da variância, incluiu-se a estimação do coeficiente de determinação genotípica $\left(\hat{H}^{2}\right)$ que expressa a confiabilidade do valor fenotípico em predizer o valor genotípico e cuja expressão é:

$$
\hat{H}^{2}=\left[\hat{\Phi}_{\mathrm{g}} / \hat{\sigma}_{\mathrm{p}}^{2}\right] \times 100,
$$

(5) Refere-se à massa em gramas pelo Sistema Internacional de Unidades. em que:

$\hat{\Phi}_{\mathrm{g}}=$ estimativa do componente quadrático associado aos efeitos genotípicos, para modelos fixos; e $\hat{\sigma}_{\mathrm{p}}^{2}=$ estimativa da variância fenotípica.

A análise dialélica foi realizada conforme Kempthorne \& Curnow (1961), para genitores e híbridos, cujo modelo estatístico, foi:

$$
\mathrm{Y}_{\mathrm{ij}}=\mu+\mathrm{g}_{\mathrm{i}}+\mathrm{g}_{\mathrm{j}}+\mathrm{s}_{\mathrm{ij}}+e_{\mathrm{ij}}^{-}
$$

em que:

$\mathrm{Y}_{\mathrm{ij}}=$ média da observação híbrida $\mathrm{ij}(\mathrm{i} \neq \mathrm{j})$ ou do i-ésimo genitor $(i=j)$;

$\mu=$ média geral;

$\mathrm{g}_{\mathrm{i}}$ e $\mathrm{g}_{\mathrm{j}}=$ efeitos da capacidade geral de combinação;

$\mathrm{s}_{\mathrm{ij}}=$ efeito da capacidade específica de combinação;

$e^{-}{ }_{\mathrm{ij}}=$ erro experimental médio.

A predição do potencial das combinações híbridas, que não foram avaliadas, foi feita por meio do estimador:

$$
Z_{i j}=\hat{\mu}+\hat{g}_{i}+\hat{g}_{j}
$$

em que:

$\mathrm{Z}_{\mathrm{ij}}=$ média predita associada à combinação híbrida ij $(\mathrm{i} \neq \mathrm{j})$;

$\hat{\mu}=$ estimativa da média geral;

$\hat{\mathrm{g}}_{\mathrm{i}}+\hat{\mathrm{g}}_{\mathrm{j}}=$ estimativas dos efeitos da capacidade geral de combinação, relativas aos genitores $i$ e $j$ (Cruz \& Regazzi, 1994).

A heterose percentual foi calculada em relação à média dos pais. Incluíram-se os híbridos 'Nápoli' e 'Super F100' para comparação com os híbridos analisados e preditos no estudo, por serem, atualmente, os mais plantados no Brasil. A comparação foi feita mediante soma de postos (ranks): consiste em classificar os genótipos em relação a cada um dos caracteres, em ordem favorável ao melhoramento, e somar os postos obtidos (Steel et al., 1997). O melhoramento busca aumentar todos os caracteres analisados neste trabalho.

Em todas as análises, utilizou-se o programa Genes (Cruz, 1997). 


\section{RESULTADOS E DISCUSSÃO}

Pelo Quadro 1, observa-se que os valores dos quadrados médios, referentes à capacidade geral de combinação (CGC) e capacidade específica de combinação (CEC), foram significativos $(\mathrm{P}<0,01)$, com exceção apenas para CEC relativa ao carácter PROD, cuja significância foi de 5\% pelo teste F. Os resultados revelam que tanto os efeitos gênicos aditivos quanto os não aditivos estão envolvidos no controle desses caracteres.

Para todos os caracteres analisados, o quadrado médio de CGC foi maior que o CEC (Quadro 1), indicando que os efeitos gênicos aditivos são mais importantes que os não aditivos. Tais resultados concordam com os obtidos por Lal \& Pathak (1974), também para berinjela. Isso indica a possibilidade de obtenção de novos cultivares, a partir do melhoramento intra- populacional na população resultante de combinação dos genitores superiores.

A constatação da maior importância da CGC para os caracteres primários da produção de frutos em berinjela indica boa precisão nas estimativas dos híbridos preditos, uma vez que esta é feita somando-se a estimativa da média geral às estimativas das CGCs dos acessos envolvidos.

Para todos os caracteres analisados (Quadro 1), obteve-se boa precisão experimental (C.V. $<16 \%$ ) e coeficiente de determinação genotípica $\left(H^{2}\right)$ acima de $80 \%$, significando alta confiabilidade dos valores fenotípicos em representar os valores genotípicos.

O Quadro 2 apresenta as estimativas dos efeitos da CGC $\left(\hat{g}_{i}\right)$ dos acessos para os cinco caracteres. Sabe-se que altas estimativas de $\hat{g}_{i}$, em valores absolutos, ocorrem para genótipos cujas freqüências de alelos favoráveis são maiores ou menores do que a freqüência média dos alelos em todos os genótipos analisados (Vencovsky, 1970) e que essas estimativas indicam a importância dos efeitos aditivos dos genes

Quadro 1. Resumo das análises da variância, estimativas dos quadrados médios da capacidade geral de combinação (CGC), da capacidade específica de combinação (CEC), média, coeficiente de variação (C.V.) e coeficiente de determinação genotípica $\left(\hat{H}^{2}\right)$ para cinco caracteres de produção de frutos em berinjela

\begin{tabular}{|c|c|c|c|c|c|c|}
\hline \multirow{2}{*}{ FV } & \multirow{2}{*}{ GL } & \multicolumn{5}{|c|}{ Quadrados Médios ${ }^{(1)}$} \\
\hline & & CMFC & DMFC & PMFC & NMFP & PROD \\
\hline Blocos ............... & 2 & 1,28 & 0,03 & 269,16 & 9,68 & 177565,82 \\
\hline Tratamentos .. & 9 & $9,71 * *$ & $7,49 * *$ & $22734,01 * *$ & $168,80 * *$ & $883341,42 * *$ \\
\hline CGC .............. & 4 & $15,74 * *$ & $13,16^{* *}$ & $39878,87 * *$ & $345,71 * *$ & $1539613,00 * *$ \\
\hline CEC ................ & 5 & $4,89^{* *}$ & $2,86^{* *}$ & $9018,13 * *$ & $27,27 * *$ & $358322,31 *$ \\
\hline $\mathrm{CGC} / \mathrm{CEC} .$. & - & 3,21 & 4,60 & 4,42 & 12,67 & 4,29 \\
\hline Resíduo .......... & 18 & 0,54 & 0,09 & 300,99 & 3,17 & 163326,01 \\
\hline Média ............. & - & 13,91 & 6,25 & 190,95 & 15,85 & 2529,06 \\
\hline C.V. $(\%) \ldots \ldots \ldots .$. & - & 5,32 & 4,88 & 9,09 & 8,59 & 15,98 \\
\hline$\hat{H}^{2}(\%) \ldots \ldots \ldots \ldots .$. & - & 94,35 & 98,75 & 98,67 & 96,41 & 81,51 \\
\hline
\end{tabular}

** $\mathrm{e} * \mathrm{P}<0,01$ e $\mathrm{P}<0,05$ respectivamente.

(1) CMFC: comprimento médio de frutos comerciais; DMFC: diâmetro médio de frutos comerciais; PMFC: peso ${ }^{(2)}$ médio de frutos comerciais; NMFP; número médio de frutos por planta; PROD; produção de frutos. ${ }^{(2)}$ Refere-se à massa em gramas pelo Sistema Internacional de Unidades. 
Quadro 2. Estimativas dos efeitos da capacidade geral de combinação $\left(\hat{g}_{i}\right)$ para cinco caracteres de cinco acessos de berinjela

\begin{tabular}{lrrrrr}
\hline \multirow{2}{*}{ Acessos } & \multicolumn{3}{c}{ Efeitos $^{(1)}$} \\
\cline { 2 - 5 } & CMFC & DMFC & PMFC & NMFP & PROD \\
\hline PI 206472 ........ & 0,88 & 0,18 & 17,23 & $-0,80$ & 375,65 \\
'Long green' ..... & $-1,33$ & $-1,47$ & $-77,36$ & 7,95 & $-323,65$ \\
'Campineira' ..... & 0,77 & 0,42 & 25,11 & $-1,97$ & 116,79 \\
'Flórida Market' & $-0,22$ & 0,93 & 48,56 & $-4,47$ & $-264,60$ \\
'E-22' .............. & $-0,09$ & $-0,07$ & $-13,54$ & $-0,70$ & $-95,81$ \\
\hline
\end{tabular}

(1) CMFC: comprimento médio de frutos comerciais; DMFC: diâmetro médio de frutos comerciais; PMFC: peso ${ }^{(2)}$ médio de frutos comerciais; NMFP: número de frutos por planta; PROD; produção de frutos. ${ }^{(2)}$ Refere-se à massa em gramas pelo Sistema Internacional de Unidades.

(Sprague \& Tatum, 1942). Nesse sentido, os acessos PI 206472 e 'Campineira' (Quadro 2) apresentaram valores positivos de $\hat{g}_{i}$ para CMFC, DMFC, PMFC e PROD, indicando boa concentração de alelos favoráveis para esses caracteres. Observa-se o mesmo comportamento para o acesso 'Florida Market' (Quadro 2), relacionado aos caracteres DMFC e PMFC, enquanto 'Long green' pode contribuir positivamente para o caráter NMFP.

Dessa forma, tais acessos podem ser utilizados em diferentes programas de melhoramento, de acordo com objetivos previamente definidos, visando à seleção de novos cultivares ou formação de híbridos (Hallauer \& Miranda Filho, 1988; Amaral Júnior et al., 1996). Em termos gerais, porém, os acessos PI 206472 e 'Campineira' foram considerados os mais promissores, por seus valores positivos de $\hat{g}_{i}$ para quatro, entre os cinco componentes primários da produção de frutos em berinjela analisados, com $\hat{g}_{i}$ negativo apenas para NMFP.

No Quadro 3, encontram-se as estimativas dos efeitos de CEC ( $\mathrm{s}_{\mathrm{ii}}$ e $\mathrm{s}_{\mathrm{ij}}$ ). Segundo Cruz \& Vencovsky (1989), $\mathrm{s}_{\mathrm{ii}}$ é uma medida da divergência genética do genitor $i$, em relação aos demais do dialelo. Assim, quanto maior o valor absoluto de $\mathrm{s}_{\mathrm{ii}}$ de um genitor, maior sua contribuição para a heterose de seus híbridos, do seguinte modo: se $\mathrm{s}_{\mathrm{ii}}$ for negativo, o genitor $i$ contribuirá positivamente para a heterose; se positivo, contribuirá negativamente. Analisando o $\mathrm{s}_{\mathrm{ii}}$ (Qua- dro 3) observam-se, com relação ao acesso n. ${ }^{\circ} 5$ ('E22'), valores negativos para os caracteres CMFC, DMFC, PMFC e PROD, podendo-se inferir que ele tenderá a expressar valores positivos de heterose para esses caracteres, quando em combinação híbrida com outros acessos analisados neste estudo, como se pode

Quadro 3. Estimativas dos efeitos da capacidade específica de combinação $\left(\mathrm{s}_{\mathrm{ii}}\right.$ e $\left.\mathrm{s}_{\mathrm{ij}}\right)$ para cinco caracteres de berinjela

\begin{tabular}{lrrrrr}
\hline \multirow{2}{*}{$\begin{array}{c}\text { Efeitos } \\
\left(\mathrm{s}_{\mathrm{ii}} \text { e }_{\mathrm{ij}}\right)\end{array}$} & \multicolumn{5}{c}{ Caracteres avaliados } \\
\cline { 2 - 6 } & CMFC & DMFC & PMFC & NMFP & PROD \\
\hline $1 \times 11^{(2)}$ & $-0,04$ & 0,11 & 1,99 & $-0,58$ & $-177,04$ \\
$1 \times 3$ & $-1,40$ & 0,54 & 32,47 & $-0,83$ & 231,83 \\
$1 \times 4$ & 1,48 & $-0,76$ & $-36,45$ & 2,00 & 122,25 \\
$2 \times 2$ & $-0,69$ & 0,34 & 13,55 & 1,05 & $-243,45$ \\
$2 \times 4$ & 0,91 & $-1,05$ & $-44,15$ & 1,65 & 531,62 \\
$2 \times 5$ & 0,48 & 0,36 & 17,04 & $-3,77$ & $-44,72$ \\
$3 \times 3$ & 0,34 & $-0,71$ & $-49,43$ & 1,67 & $-175,50$ \\
$3 \times 5$ & 0,71 & 0,88 & 66,40 & $-2,51$ & 119,17 \\
$4 \times 4$ & $-1,19$ & 0,91 & 40,30 & $-1,82$ & $-326,93$ \\
$5 \times 5$ & $-0,60$ & $-0,62$ & $-41,72$ & 3,14 & $-37,22$ \\
\hline
\end{tabular}

(1) CMFC: comprimento médio de frutos comerciais; DMFC: diâmetro médio de frutos comerciais; PMFC: peso $^{(3)}$ médio de frutos comerciais; NMFP: número médio de frutos por planta; PROD: produção de frutos. ${ }^{(2)} 1$ : PI 206472; 2: 'Long green'; 3 : 'Campineira'; 4: 'Flórida Market'; 5: 'E-22'. (3) Refere-se à massa em gramas pelo Sistema Internacional de Unidades. 
verificar no Quadro 4. O acesso n. ${ }^{\circ}$ 4, 'Florida Market', pode ser utilizado em programas de melhoramento que visem ao aumento do número de frutos por planta (NMFP), pois apresenta valor negativo de $\mathrm{s}_{\mathrm{ii}}$ (Quadro 3) e os híbridos com maiores valores de heterose (Quadro 4), para esse caráter. Para CMFC, DMFC, PMFC e NMFP, existem acessos com valores de $s_{i i}$ positivos e negativos, ilustrando a hipótese de dominância bidirecional, segundo a qual existem genes dominantes que aumentam a expressão do caráter, e outros, igualmente dominantes, que a reduzem (Cruz \& Vencovsky, 1989).
Valores de $\mathrm{s}_{\mathrm{ij}}$ (Quadro 3) são diretamente proporcionais à heterose, uma vez que a média dos híbridos analisados é obtida somando-se à estimativa da média geral as CGCs dos acessos e a CEC. Nesse aspecto, entre os híbridos analisados, o $2 \times 4$ ('Long green' x 'Flórida Market'), cujo $\mathrm{s}_{\mathrm{ij}}$ é o maior para o caráter PROD (Quadro 3), apresenta o maior valor de heterose para esse caráter (Quadro 4). Comportamento similar pode ser observado para o híbrido $3 \times 5$ ('Campineira' $x$ 'E-22'), com valores positivos de $s_{i j}$ para os caracteres CMFC, DMFC, PMFC e PROD, indicando, assim, seus valores positivos de heterose (Quadro 4) para tais caracteres.

Quadro 4. Estimativas das médias de cinco acessos de berinjela e de seus respectivos híbridos e heterose percentual, referente a cinco componentes da produção de frutos em berinjela

\begin{tabular}{|c|c|c|c|c|c|c|c|c|c|c|}
\hline \multirow{3}{*}{ Genótipos } & \multicolumn{10}{|c|}{ Caracteres $^{(1)}$} \\
\hline & \multicolumn{2}{|c|}{ CMFC } & \multicolumn{2}{|c|}{ DMFC } & \multicolumn{2}{|c|}{ PMFC } & \multicolumn{2}{|c|}{ NMFP } & \multicolumn{2}{|c|}{ PROD } \\
\hline & Média & Heterose & Média & Heterose & Média & Heterose & Média & Heterose & Média 1 & Heterose \\
\hline & $\mathrm{cm}$ & $\%$ & $\mathrm{~cm}$ & $\%$ & $\mathrm{~g}$ & $\%$ & n. ${ }^{\circ}$ & $\%$ & $\mathrm{~g} / \mathrm{pl}$ & $\%$ \\
\hline $1^{(2)}$ & 15,63 & - & 6,73 & - & 227,42 & - & 13,66 & - & 3103,33 & - \\
\hline 2 & 10,54 & - & 3,65 & - & 49,77 & - & 32,83 & - & 1638,28 & - \\
\hline 3 & 15,80 & - & 6,38 & - & 191,75 & - & 13,58 & - & 2587,14 & - \\
\hline 4 & 12,26 & - & 9,04 & - & 328,38 & - & 5,08 & - & 1672,91 & - \\
\hline 5 & 13,11 & - & 5,47 & - & 122,13 & - & 21,75 & - & 2683,45 & - \\
\hline$\bullet 1 \times 2^{(3)}$ & 13,45 & 2,79 & 4,96 & $-4,43$ & 130,82 & $-5,60$ & 22,79 & $-1,93$ & 2581,04 & 8,86 \\
\hline$+1 \times 3^{(4)}$ & 14,16 & $-9,89$ & 7,41 & 13,12 & 265,77 & 26,81 & 12,25 & $-10,05$ & 3253,33 & 14,34 \\
\hline$+1 \times 4$ & 16,05 & 15,09 & 6,61 & $-16,16$ & 220,29 & $-20,73$ & 12,58 & 34,25 & 2762,36 & 15,67 \\
\hline$\bullet 1 \times 5$ & 14,69 & 2,22 & 6,36 & 4,26 & 194,64 & 11,36 & 15,85 & $-10,47$ & 3000,52 & 3,70 \\
\hline$\bullet 2 \times 3$ & 13,34 & 1,29 & 5,20 & 3,68 & 138,70 & 14,85 & 21,34 & $-8,03$ & 2322,19 & 9,91 \\
\hline$+2 \times 4$ & 13,26 & 16,31 & 4,66 & $-26,55$ & 117,99 & $-37,59$ & 21,00 & 10,78 & 2472,42 & 49,33 \\
\hline$+2 \times 5$ & 12,96 & 9,59 & 5,06 & 10,96 & 117,08 & 36,22 & 19,33 & $-29,16$ & 2256,48 & 4,42 \\
\hline$\bullet 3 \times 4$ & 14,45 & 2,99 & 7,61 & $-1,29$ & 264,63 & 1,75 & 9,19 & $-1,50$ & 2381,25 & 11,79 \\
\hline$+3 \times 5$ & 15,30 & 5,84 & 7,48 & 26,24 & 268,92 & 71,35 & 10,66 & $-39,65$ & 2860,83 & 8,55 \\
\hline$\bullet 4 \times 5$ & 13,58 & 7,05 & 7,11 & $-1,99$ & 225,96 & 0,31 & 12,18 & $-9,20$ & 2360,26 & 8,35 \\
\hline
\end{tabular}

(1) CMFC: comprimento médio de frutos comerciais; DMFC: diâmetro médio de frutos comerciais; PMFC: peso ${ }^{(5)}$ médio de frutos comerciais; NMFP: número médio de frutos por planta; PROD: produção de frutos.

(2) 1: PI 206472; 2: 'Long green'; 3: 'Campineira'; 4: 'Flórida Market'; 5: 'E-22'.

(3) : Híbrido predito.

(4) +: Híbrido analisado.

(5) Refere-se à massa em gramas pelo Sistema Internacional de Unidades. 
Quadro 5. Comparação das estimativas das médias de cinco caracteres, de híbridos preditos e analisados, com híbridos comerciais, por meio de soma de rank em berinjela

\begin{tabular}{|c|c|c|c|c|c|c|c|c|c|c|c|}
\hline \multirow{3}{*}{ Híbridos $^{(1)}$} & \multicolumn{10}{|c|}{ Caracteres $^{(2)}$} & \multirow{3}{*}{$\begin{array}{c}\text { Soma } \\
\text { de } \\
\text { rank }\end{array}$} \\
\hline & \multicolumn{2}{|c|}{ CMFC } & \multicolumn{2}{|c|}{ DMFC } & \multicolumn{2}{|c|}{ PMFC } & \multicolumn{2}{|c|}{ NMFC } & \multicolumn{2}{|c|}{ PROD } & \\
\hline & Média & Rank & Média & Rank & Média & Rank & Média & Rank & Média & Rank & \\
\hline$\bullet 1 \times 2^{(3)}$ & 13,45 & 04 & 4,96 & 02 & 130,82 & 03 & 22,79 & 12 & 2581,04 & 08 & 29 \\
\hline$+1 \times 3^{(4)}$ & 14,16 & 06 & 7,41 & 10 & 265,77 & 11 & 12,25 & 06 & 3253,33 & 12 & 45 \\
\hline$+1 \times 4$ & 16,05 & 12 & 6,61 & 06 & 220,29 & 06 & 12,58 & 07 & 2762,36 & 09 & 40 \\
\hline$\bullet 1 \times 5$ & 14,69 & 08 & 6,36 & 05 & 194,64 & 05 & 15,85 & 08 & 3000,52 & 11 & 37 \\
\hline$\bullet 2 \times 3$ & 13,34 & 03 & 5,20 & 04 & 138,70 & 04 & 21,34 & 11 & 2322,19 & 02 & 24 \\
\hline$+2 \times 4$ & 13,26 & 02 & 4,66 & 01 & 117,99 & 02 & 21,00 & 10 & 2472,42 & 05 & 20 \\
\hline$+2 \times 5$ & 12,96 & 01 & 5,06 & 03 & 117,08 & 01 & 19,33 & 09 & 2256,48 & 01 & 15 \\
\hline$\bullet 3 \times 4$ & 14,45 & 07 & 7,61 & 12 & 264,63 & 10 & 9,19 & 01 & 2381,25 & 04 & 34 \\
\hline$+3 \times 5$ & 15,30 & 09 & 7,48 & 11 & 268,92 & 12 & 10,66 & 03 & 2860,83 & 10 & 45 \\
\hline$\bullet 4 \times 5$ & 13,58 & 05 & 7,11 & 07 & 225,96 & 07 & 12,18 & 05 & 2360,26 & 03 & 27 \\
\hline Nápoli $^{(5)}$ & 15,81 & 11 & 7,24 & 09 & 252,35 & 09 & 9,83 & 02 & 2482,91 & 06 & 37 \\
\hline Super F100 & 15,48 & 10 & 7,12 & 08 & 236,33 & 08 & 10,83 & 04 & 2549,16 & 07 & 37 \\
\hline
\end{tabular}

(1) 1: PI 206472; 2: 'Long green'; 3: 'Campineira'; 4: 'Flórida Market'; 5: 'E-22'.

${ }^{(2)} \mathrm{CMFC}$ : comprimento médio de frutos comerciais; DMFC: diâmetro médio de frutos comerciais; PMFC: peso ${ }^{(6)}$ médio de frutos comerciais; NMFP: número médio de frutos por planta; PROD: produção de frutos.

(3) : Híbrido predito.

(4) + : Híbrido analisado.

(5) Híbrido comercial.

(6) Refere-se à massa em gramas pelo Sistema Internacional de Unidades.

Comparando-se as médias dos híbridos 'Nápoli' e 'Super F100' com os analisados e preditos (Quadro 5), por meio da soma de posto rank, detecta-se que os híbridos $1 \times 3,1 \times 4,1 \times 5$ e $3 \times 5$ apresentaram posição de rank igual ou superior aos híbridos mais plantados no Brasil. Demonstram, assim, forte potencial comercial, uma vez que atendem a todas as exigências do mercado com relação às características qualitativas, quais sejam: cor, brilho, forma, textura e sabor.

Merece destaque o híbrido 1 x 5 (PI 206472 x 'E-22'), cujas médias foram preditas e, portanto, sem o efeito de $\mathrm{s}_{\mathrm{ij}}$, e, mesmo assim, apresentou posição de rank igual à do híbrido 'Nápoli', sendo, pois, viável sua análise em futuros estudos.

\section{CONCLUSÕES}

1. Os efeitos gênicos aditivos predominaram na expressão de todos os caracteres analisados.

2. Os cultivares 1 (PI 206472) e 3 (Campineira) foram os mais indicados para programas de melhoramento genético intrapopulacionais, em função da sua CGC para os caracteres analisados.

3. Os cruzamentos 1 x 3 (PI 206472 x 'Campineira'), 1 x 4 (PI 206472 x 'Flórida Market'), 1 x 5 (PI 206472 x 'E-22') e 3 x 5 ('Campineira' $x$ 'E-22'), tiveram alto potencial para gerar híbridos economicamente superiores. 


\section{AGRADECIMENTOS}

À CAPES/PICDT, pela concessão de bolsa de estudos.

\section{REFERÊNCIAS BIBLIOGRÁFICAS}

AMARAL JÚNIOR, A.T.; CASALI, V.W.D.; SCAPIM, C.A.; SILVA, D.J.H. \& CRUZ, C.D. Análise dialélica da capacidade combinatória de cultivares de tomateiro. Bragantia, Campinas, 55(1):67-73, 1996.

BOLETIM MENSAL CEAGESP, São Paulo, CEAGESP n.12, dez., 1994.

CRUZ, C.D. Programa Genes: aplicativo computacional em genética e estatística. Viçosa, UFV, 1997. 442p.

CRUZ, C.D. \& REGAZZI, A. J. Modelos biométricos aplicados ao melhoramento genético. Viçosa, Imprensa Universitária - UFV, 1994. 390 p.

CRUZ, C.D. \& VENCOVSKY, R. Comparação de alguns métodos de análise dialélica. Revista Brasileira de Genéti$c a$, Ribeirão Preto, 12(2):425-438, 1989.

DANTAS, A C. V. L. Cruzamento dialélico parcial circulante para avaliação de linhagens de milho (Zea mays L.) e predição de híbridos. Piracicaba, 1988. 153p. Dissertação (Mestrado em Genética e Melhoramento de Plantas) - ESALQ/USP, 1988.

FILGUEIRA, F.A.R. Manual de olericultura: cultura e comercialização de hortaliças. 2.ed., São Paulo, Agronômica Ceres, 1982. v.2, 357p.

GONÇALVES, P. Esquema circulante de cruzamentos para avaliação de linhagens de milho (Zea mays L.) ao nivel interpopulacional. Piracicaba, 1987. 140 p. Tese (Doutorado em Genética e Melhoramento de Plantas) - ESALQ/ USP, 1987.
HALLAUER, S. R. \& MIRANDA FILHO, J. B. Quantitative genetics in maize breeding. 2.ed., Ames, Iowa State University Press, 1988. 468p.

KEMPTHORNE, O. \& CURNOW, R.N. The partial diallel cross. Biometrics, Alexandria, 17:229-250, 1961.

LAL, S. \& PATHAK, M.M. Combining ability in brinjal. Indian Journal. of Genetics. and Plant Breeding, New Delhi, 34(3): 395-399, 1974.

NODA, H. Critérios de avaliação de progênies de irmãos germanos interpopulacionais em berinjela (Solanum melongena L.). Piracicaba, 1980. 91p. Dissertação (Mestrado em Genética e Melhoramento de Plantas) ESALQ/USP, 1980.

RAMALHO, M.A.P.; SANTOS, J.B. \& ZIMMERMAN, M.J.O. Genética quantitativa aplicada em plantas autógamas: aplicação ao melhoramento do feijoeiro. Goiânia, Universidade Federal de Goiás, 1993. 217p.

RUSSEL, W. A. \& EBERHART, S.A. Hybrid performance of select maize lines from reciprocal recurrent selection and testcross selection programs. Crop Science, Madison, 15:1-4, 1975.

SPRAGUE, G.F. \& TATUM, L.A. General vs specific combining ability in single crosses of corn. Journal of the American Society of Agronomy, Washinghton, 34:923-932, 1942.

STEEL, R.G.D.; TORRIE, J.H. \& DICKEY, D.A. Principles and procedures of statistics: a biometrical approach. 3.ed. New York, McGraw-Hill, 1997. 666p.

VENCOVSKY, R. Alguns aspectos teóricos e aplicados relativos a cruzamentos dialélicos de variedades. Piracicaba, 1970. 59p. Tese (Livre-Docência em Genética e Melhoramento de Plantas) - ESALQ/USP, 1970. 